upon the author, and we would express the hope that it may soon be available for the English reader, especially as the only comparable volume, namely, Vogt's Atlas, is now out of print.

Revista Oto-Neuro-Oftalmologica y de Cirurgia Neurologica. Buenos Aires. July and August, 1927.

A new Spanish ophthalmological journal has made its appearance at Buenos Aires named as above. The first two numbers are very well printed and illustrated. The directors are Dr. Lijo Pavia and Dr. Roque Orlando. There are other wellknown names in the list of the Committee and Secretaries.

The first article in the first number, which is continued in the second, is by Pavia on the photography of the fundus. He uses the Dimmer method with the Gullstrand stationary ophthalmoscope, constructed by Zeiss, and he explains the use of the instrument and the adaptability of the ocular fundus photographs for clinical records.

Trachoma. Thesis for the National University of Buenos Aires. By Marcello Dusseldorp. Buenos Aires. 1927.

The author has published a book of 200 pages on trachoma, which exhibits him not merely as a careful student of the modernliterature on trachoma, but also as a discriminating surgeon acquainted with all modern methods of treatment of the disease. He recognizes the importance of the division of the various phases of trachoma according to their evolution, MacCallan's stages of trachoma. He also lays stress on the necessity of using the slitlamp in the diagnosis of doubtful cases of trachoma. There is no doubt that in cases in which the diagnosis of trachoma is suspected, but is not certain, no opinion should be given before a careful slitlamp examination has been madr.

\title{
CORRESPONDENCE
}

\section{EXAMINATION OF THE FUNDUS BY RED-FREE LIGHT}

To the Editor of The British Journal of Ophthalmology SiR,-I am much obliged to the reviewer of "Recent Advances in Ophthalmology" by Mr. Duke-Elder for emphasizing that I first introduced the mercury vapour lamp for the examination of the eye (Trans. Ophthal. Soc. U.K., 1903), and for alluding to the 
fact that extensive trial was given to it at the time. I would like to point out also that the paper states that similar results can be obtained by using a Gifford's F. line screen in front of an arc lamp, showing that other forms of red-free light were tried. Although the paper is a brief one, it summarizes practically all the points which have been brought forward again recently which, although of interest, are of no great practical value.

Yours truly,

M. S. Mayou.

\section{NOTES}

Death

WE regret to record the death on January 7 of Mr. LEon Gaster. He was the founder of the Illuminating Engineering Society, and he was responsible for creating an impartial platform for the discussion of all problems relating to illumination, natural and artificial. He deserved great credit for the breadth of his views, especially in recognizing the medical and hygienic aspect of illumination. He was largely responsible for convincing the Home Office of the advisability of forming a Departmental Committee on factory lighting, which proved a step towards the formation of a permanent committee, which is now in being as the Illumination Committee of the Department of Scientific and Industrial Research.

\section{Registration} of Opticians

THE report of the Departmental Committee appointed last year to consider this subject has been issued, consisting of a majority and two minority sections. The majority report is to the effect that a State register of sight-testing opticians is not in itself a desirable policy. We hope to comment more at length in our next number.

Royal London

THE annual dinner of past and present students Ophthalmic Hospital of Moorfields Hospital will be held at the Dinner

Langham Hotel, on Wednesday, February 8 at 7.30 p.m. Sir Wilmot Herringham, K.C.M.G., C.B., in the chair. Tickets, 15s. (exclusive of wine), may be obtained from Sir William Lister, 24, Devonshire Place, W.1. A remittance with application will save great inconvenience. 